\title{
Building planetary surfaces
}

\author{
Lionel Wilson
}

Volcanoes of the Solar System. By Charles Frankel. Cambridge University Press: 1996. Pp. 232. \$69.95, £40 (hbk); \$24.95, 114 (pbk).

THE planetary exploration missions of the past two decades have shown that volcanic activity is by far the most important mechanism forming the crusts of the silicatedominated bodies in the Solar System. Volcanic eruptions in various guises and at various times have constructed more than three-quarters of the surface features of Earth and Venus, half of the surface area of Mars and at least a quarter of the surface of our Moon - even more in both of the latter cases if one counts as a volcanic

\section{IMAGE UNAVAILABLE FOR COPYRIGHT REASONS}

\section{Volcanoes build planet surfaces: erupution on lo.}

phenomenon the solidification of the global molten-magma oceans generated by the rapid accretion of these bodies. Only Mercury among the inner planets has still to be imaged at high enough resolution for specific volcanic features on its surface to be recognized unequivocally. And recent analyses of some of the rocks in the world's meteorite collections have shown that several small asteroids have had significant volcanic histories.

In retrospect, we should not be surprised that volcanism is so widespread: advective transport of molten rock to the surface of a planet is a much more efficient method of removing heat from the interior than thermal conduction through the essentially rigid crust. The timing and duration of volcanic activity on a body is a delicately balanced matter, however. With the smaller bodies, for which the most important heat source, other than the kinetic energy of accretion itself, was the decay of short-lived radioactive isotopes, activity was inevitably confined to the early part of Solar System history. The larger bodies, with smaller ratios of surface area to volume, and so a greater efficiency of heat generation relative to heat loss, have been forced to cope with the energy produced by the long-lived isotopes of potassium, uranium and thorium, the main elements that power Earth and (almost certainly) Venus. Jupiter's satellite Io, although smaller than the Moon, is still vigorously volcanically active today, but only because it derives heat from the enormous body tide generated within it by nearby Jupiter as two of the other satellites, Europa and Ganymede, exert mutual gravitational nudges that distort its orbit and lead to their own heating, albeit at much lower levels.

All the above issues are presented and discussed with disarming simplicity in Charles Frankel's excellent summary of planetary volcanism. Higho ples of the main types of volcanic feature (lava flows, . ash deposits, volcanic moun응 tains, and collapse and explo$\circlearrowleft$ sion craters) visible on all the

s active bodies in the Solar System. If this were all that the book accomplished, I would count it as a useful addition to the literature. But there is much more. Frankel describes in great detail the physical principles that control the formation of volcanic features, showing how the sizes and shapes of edifices and deposits are related to the amounts and physicochemical properties (viscosity, dissolved volatile content and so on) of magmas reaching the surfaces of planets and to the environmental conditions into which they emerge. It is specifically this comparison of the sizes, shapes and chemical compositions of volcanic deposits formed under differing environmental conditions (especially those of gravity, atmospheric pressure and crustal stress) that has led to so many advances during the past 20 years in the understanding of volcanism as a general process.

Attempting to deal with so much basic geology and geophysics in a work aimed mainly at a general audience must have been a daunting task, but Frankel has succeeded amazingly well in assimilating and conveying to his readers the essentials of modern theoretical volcanology as applied to both Earth and the other planets. Of course, many issues are simplified, although I found nothing that I regard as a major error. Indeed, the simplification almost always manages to leave the reader with the correct general impression of what is going on, so that only further elaboration, rather than a complete return to basics, would be needed to present a more sophisticated story. I was repeatedly delighted to see how well this had been done - an object lesson to all writers of first-year undergraduate textbooks.

Several highlights stand out: the engaging accounts of the Apollo astronauts doing their best to carry out field geology in the extremely harsh lunar environment, followed by an erudite discussion of what the rocks collected on the Apollo missions have told us about lunar geological history and, by implication and inference, the history of the larger planets; a description of a hypothetical field trip to the summit area of the Martian volcano Olympus Mons, setting the scene for an understanding of the immense lengths of time during which some Martian volcanoes were active over hot-spots in the mantle; and a reminder of the excitement (terror?) of standing near a flow of liquid sulphur on Io and watching its completely unexpected behaviour as, for a while, it becomes more fluid, rather than less fluid, as it cools.

As an up-to-date, easily readable, accurate and enjoyable introduction to all aspects of planetary volcanology, I cannot imagine this book being bettered for some time.

Lionel Wilson is at the Institute of Environmental and Biological Sciences, University of Lancaster, Lancaster LA1 4YQ, UK.

\section{Back on Earth (in paperback)}

Principles of Precambrian Geology by Alan M. Goodwin. Academic, £35 (pbk). An abridgement of the author's acclaimed book Precambrian Geology, published in 1991.

Human Impact on the Earth by William B. Meyer. Cambridge University Press, £40, \$69.95 (hbk), £12.95, \$24.95 (pbk). A slimmed-down, updated version of the landmark volume The Earth as Transformed by Human Action edited by B. L. Turner et al., which was described by Cynthia Rosenzweig and Daniel Hillel in these pages as "an indispensable reference and resource on global change... instructive and challenging". Nature 355, 781 (1992).

Global Tectonics by Philip Kearey and Frederick J. Vine, second edition. Blackwell, £22.50 (pbk). A textbook intended for senior undergraduates in the geological science, and postgraduate students and other geoscientists who wish to gain an insight into the subject. In his review of the first edition, however, Peter J. Smith complained that "from the teaching point of view the book is not quite basic enough... it too often fails to explain". Nature 350, 200 (1990). 